\title{
Firm growth and its determinants
}

\author{
Priya Dhamija Gupta1*, Samapti Guha ${ }^{2}$ and Shiva Subramanian Krishnaswami ${ }^{1}$
}

\author{
*Correspondence: priya_gupta@ \\ scmhrd.edu \\ ${ }^{1}$ Symbiosis Centre for Management \\ and Human Resource Management, \\ Pune 4110457, India \\ Full list of author information is \\ available at the end of the article
}

\begin{abstract}
Enterprise growth has been studied by researchers for many years. Different terms have been used by different authors to define the stages of an enterprise growth, but the events through which each enterprise passes remain more or less the same. Most of the researchers suggest that each enterprise has to start, then grow while facing various challenges and crises, and finally mature and decline. There are many factors which will contribute to an enterprise's success. There are many precursors also, which will allow an enterprise to move from one stage to another. There are two sets of thought prevailing among researchers; some suggest that the growth path followed by the enterprise is linear or predictable, and others suggest that the growth is fairly opportunistic or unpredictable. The understanding of the growth of an enterprise depends on the definition of what the firm is, how much has it grown, and what it offers to the market? What assets it controls and what is its legal form. It is critical to study how an enterprise manages its growth transitions and what pattern they follow. In this paper, a framework has been designed to study the path followed by small and medium enterprises (SMEs). This framework considered the influence of internal and external environmental factor on the growth patterns of SMEs. The paper encompasses literature review on various theories of enterprise growth. It highlights that though there are many studies on the stages of enterprise development, there is a dearth of literature on finding patterns of growth followed by the small and medium enterprises. Also, there is lack of literature on the effect of environmental factors in determining growth path. There is a need of a framework which can help the industry to empirically test enterprise growth patterns under different conditions.
\end{abstract}

Keywords: Small and medium enterprises, Enterprise life cycle, Business environment

\section{Review \\ Background}

Enterprise growth has been an area of study for many researchers. The study of literature on small and medium enterprises (SMEs) suggests that all SMEs go through different stages of growth, also commonly called as life cycles. Though the terms used by different authors may vary, the events through which each enterprise passes remain more or less the same. Most of the researchers suggest that each enterprise has to start, then grow while facing various challenges and crises, and finally mature and decline. There are many factors which will contribute to an enterprise's success. There are many precursors also, which will allow an enterprise to move from one stage to another. History of the enterprise, entrepreneur's characteristics, different agencies (like market, government, etc.), and geography are some of the factors influencing an enterprise's growth. There are two sets of

\section{Springer}

(c) 2013 Gupta et al.; licensee Springer. This is an Open Access article distributed under the terms of the Creative Commons Attribution License (http://creativecommons.org/licenses/by/2.0), which permits unrestricted use, distribution, and reproduction in any medium, provided the original work is properly cited. 
thought prevailing among researchers; some suggest that the growth path followed by the enterprise is linear or predictable, and others suggest that the growth is fairly opportunistic term or unpredictable. Growth-oriented firms are a significant contributor in a nation's economic gain, but the concept of growth is different for different entrepreneurs. Growth can be defined in terms of revenue generation, value addition, and expansion in terms of volume of the business. It can also be measured in the form of qualitative features like market position, quality of product, and goodwill of the customers. While studying the growth of a firm, it is essential to understand the concept of 'the firm' also. The understanding of the growth of an enterprise depends on the definition of what the firm is, how much has it grown, and what it offers to the market? What assets it controls and what is its legal form.

It is critical to study how an enterprise manages its growth transitions and what pattern they follow. Most widely used framework for studying the growth of an enterprise has been the life cycle analysis. In life cycle models, an enterprise's growth is considered as organic, and these assumed that this growth happens over a period of time in a linear phase. However, there are many researches suggesting that it may not be the case with every enterprise. Many firms do not take the linear path because it is not possible for each of those to progress through each stage. They can grow, stagnate, and decline in any order. Also, these things can happen more than once, and there is a possibility to reverse their steps.

Enterprise growth can be identified in four theoretical perspectives: the resource-based perspective, the motivation perspective, the strategic adaptation perspective and the configuration perspective. Resource-based perspective focuses on the enterprises' resources like expansion of business activities, financial resources, educated staff, etc. Resource-based theory holds that there are unlimited sources of opportunities in the marketplace. It is essential to manage transition (i.e., the point at which the resources are being reconfigured) by deploying firms' resources to identify and exploit the next growth opportunity. Hence, to determine successive phases of growth and development, resources need to be reconfigured during the transitions between stages. To conclude, there is limited study on the growth path of SMEs. During the literature review, it has been observed that study on enterprise growth has still not covered many prominent sectors like handicraft, handloom, etc. which constitutes large number of SMEs. This paper encompasses literature review on various theories of enterprise growth. It highlights that though there are many studies on the stages of enterprise development, there is a dearth of literature on finding patterns of growth followed by the small and medium enterprises. Also, there is lack of literature on the effect of environmental factors in determining the growth path. This paper suggests a need for a framework which can be empirically tested by researchers to study enterprise growth patterns under different conditions. This paper is organized as follows. Section 2 presents the state of work done in the area of small and medium enterprises, entrepreneurship and enterprise growth based on the literature reviewed for this study. Section 3 introduces the conceptual framework. Next, Section 4, outline the gaps identified in research so far.

\section{Literature review}

\section{Entrepreneurship and enterprise growth}

Entrepreneurship is all about the identification of an opportunity, creation of new organization, and pursuing new ventures (Carton et al. 1998). There are many studies 
done on entrepreneurship like external skills required in entrepreneurs. For example, Schumpeter (1934) has stated that an entrepreneur needs to be innovative, creative, and should be able to take risk. Wickham (2006) has also supported his views. Pajarinen et al. (2006) have said that entrepreneurs with higher academic background are more innovative and will use modern techniques and models to do business. Barringer and Bluedorn (1999) have described entrepreneurs as individuals who can explore the environment, discover the opportunities, and exploit them after proper evaluation. Kuratko (2009), in his book, distinguishes between entrepreneurs and small business owners. He highlights that these two terms are often used interchangeably, but both have a lot of differences in their reaction under certain situations. An entrepreneur aggressively focuses on innovation profit and growth of the enterprise. On the other hand, a small business owner's objective and focus is mostly on managing stable growth, sales, and profits.

An entrepreneurial venture is successful if it is growing. Growth has various connotations. It can be defined in terms of revenue generation, value addition, and expansion in terms of volume of the business. It can also be measured in the form of qualitative features like market position, quality of product, and goodwill of the customers (Kruger 2004).

As stated earlier, growth is a vital indicator of a flourishing enterprise. There are many factors like characteristics of the entrepreneur, access to resources like finance, and manpower which affect the growth of the enterprise and differentiate it from a non-growing enterprise. Gilbert et al. (2006) suggested how and where questions are important in the context of the growth of the enterprise. It has been highlighted that growth is a function of the decisions an entrepreneur makes, like how to grow internally or externally and where to grow in domestic market or international market. There are many different theories on identifying the main factors underlying the growth of the enterprise. One set of theories addressed the influence of enterprise size and age on growth (Evans 1987; Heshmati 2001; Morone and Testa 2008), and the second set deals with the influence of variables such as strategy, organization, and the characteristics of the enterprise's owners (Fazzari et al. 1988; Lumpkin and Dess 1996; Freel and Robson 2004) on growth of the enterprise. Mateev and Anastasov (2010) have found that an enterprise's growth is related to size as well as other specific characteristics like financial structure and productivity. They further added that the total assets which is one of the measure of the enterprise size has a direct impact on the sales revenue, but the number of employees, investment in R \& D, and other intangible assets have not much influence on the enterprise's growth prospects. Lorunka et al. (2011) have found that the gender of the founder, the amount of capital required at the time of starting the business, and growth strategy of the enterprise are very important factors in predicting growth in a small enterprise. They have further highlighted that apart from human capital resources, the growth of an enterprise can be predicted on the basis of commitment of the person starting a new enterprise.

\section{SMEs, innovation and economic development}

SMEs are considered as the backbone of the economy. SME sector is well recognized worldwide due to its significant contribution in socio-economic development. This sector has contributed significantly in higher growth of employment, output, promotion of 
exports, and fostering entrepreneurship. Many countries have given sufficient emphasis to micro, small, and medium enterprises, and have identified them as a building block for their economic development. Market conditions have changed for SMEs after economic reforms; organizations are in constant pressure to perform well, deliver quality, and keep their operational cost low. To sustain in today's market and meet customers', it has become important for organizations to differentiate themselves on the basis of capabilities and competencies. They need to compete on different dimensions such as design and development of products, manufacturing, cost, distribution, communication, and innovative ways of marketing. These challenges call for reorientation of SMEs, so that the demand for high dynamism, flexibility, and innovativeness can be met. For economic development, it is critical for SMEs to create, apply, and introduce innovation (Curran and Blackburn 1994). It has been found that in the previous century, 60\% of the innovations were in the SME sector, but many of them were not successful due to lack of professionalism and inability to collaborate with other enterprises (Rothwell 1986; Noteboom 1991; Bougrain and Haudeville 2002).

There is no universal definition of SMEs. Countries have used various criterions to define SMEs. Some countries use turnover of the company to determine the size of an enterprise, whereas some use fixed investment or the number of employees (Lokhande 2011), sales volume, and worth of assets (Rahman 2001). In India, as per the Micro, Small and Medium Enterprises Development Act of 2006, micro, small and medium enterprises are classified in two classes: manufacturing enterprises and service enterprises. The enterprises engaged in the manufacturing or in the production of goods are defined in terms of investment in plant and machinery.

- A small scale industry is defined on the basis of limit of value of investment in plant and machinery, which is more than 25 lakh rupees and does not exceed five crore rupees.

- A medium scale industry is defined on the basis of the value of investment in plant and machinery, which is more than five crore rupees but does not exceed ten crore rupees.

In India, the focus is more on the investment amount, whereas most of the other countries define SMEs in terms of number of employees and turnover. According to The SME Whitebook 2009-2010 (The Business World 2010), 'In Malaysia, small enterprises have a turnover between rupees two lakh fifty thousand to one million and medium enterprises have a turnover between one million and twenty five million. Also, the average employee strength for SMEs is fifty employees and one hundred fifty employees respectively. In Hong Kong, the definition of SME is given by the Government of Hong Kong Special Administrative Regions (HKSAR). According to the HKSAR, a manufacturing business that employs fewer than hundred persons...' Further, 'In China, small enterprises are defined as those that employ fifty to hundred people and medium enterprises employ hundred one to one hundred fifty people. In the European Union (EU), a business with a headcount of fewer than two hundred fifty is classified as medium sized, a business with a headcount of fewer that fifty is classified as small. In United Kingdom (UK), a small enterprise as a unit has a turnover of $£ 5.6$ million, and employs around fifty people. A medium sized enterprise has a turnover of $£ 22.8$ million 
and has two hundred fifty employees. Canada defines a small business as one that has around fifty to hundred employees depending on service and manufacturing respectively. A firm that has around five hundred employees is classified as a medium sized business. In Japan, for the manufacturing sector, SMEs are those that employ less than three hundred people or have an invested capital of less than hundred million yen. In the United States of America, an SME means a unit consisting of one thousand five hundred employees and has a turnover of around $\$ 0.75$ to 29 million, depending upon the type of business. In the US a government department called small business administration (SBA) sets the definition of small businesses'.

\section{Significance of growth in SMEs}

SMEs are considered as a major source of employment generation also. It has the advantage of cheap labor and flexibility of operations along with indigenizing technology (Mitra and Pingali 1999). There are a large number of studies suggesting that small businesses play a major role in job creation (Smallbone and Wyer 2000). Though there are many arguments on the overall contribution of small businesses in the new employment, it is considered as an important source for employment creation (Curran 2000; Davidsson and Delmar 1997; Gibb 2000; Hamilton and Dana 2003; Robbins et al. 2000; Tonge et al. 2000; Westhead and Birley 1995). Baumol (2004) suggests that small entrepreneurial organizations and entrepreneurs will always be considered important for growth of developing economies. Hence, it is critical to pay attention on the overall growth of this sector. There are different views on the growth of SMEs. The existing body of knowledge covers different factors influencing the growth of small firms. Some of the work is being discussed in this section to highlight different views on SMEs and growth.

Chaston and Mangles (1997) suggest that if an enterprise adopts multi-strategy transformation initiatives, the probability of achieving the growth objective increases. They further points that in planning a performance improvement program, different capabilities must be given priority depending upon the development stage of the firm. In their study, Kolvereid and Bullvag (1996) found that almost 40\% of the respondents do not want to grow. Further, they found that there is a significant relation between education, industry, past growth turnover, past growth in employees, and entrepreneur's aspiration to grow. Aspirations are also significantly related to many factors like experience, sex, location, and size of the firm. They concluded that entrepreneurs who want their firm to grow will have higher level of education and will tend to have manufacturing firms rather than service firms. Government has included many promotional policies for the promotion of this sector like product reservation, infrastructure support, direct and concessional credit, tax concession, special assessment in procurement of equipment, facility of duty drawback, quality control, and provision of market network. Small scale companies provide support to large scale companies by supplying goods and services in small quantities, which in turn help them to achieve competitive advantage (Majumdar 2007). Muthaih and Venkatesh (2012) suggest that many factors contribute in the SME growth; similarly, there are many barriers to growth. For small businesses, barriers can be of two types, institutional and financial. An institutional barrier includes the enterprise's interaction with government, issues related to legalization, taxation, and government support. Financial barriers will involve lack of financial resources 
(Davidsson 1989). Further, the authors notice that SMEs can also face external and internal barriers along with social barriers which would cover aspects of market position of an enterprise, access to right kind of human resources, and access to network (Bartlett and Bukvic 2001). Studies have shown that there are many other factors that would contribute to the failure of a small firm/business. Small businesses are dependent on the owner's insight, managerial skills, training, education, and the background of the company's leader. Often, lack of these characteristics is the cause of small business' failure (Gaskill et al. 1993).

\section{Theoretical frame work to study the growth path of enterprises}

To study the growth path of the enterprises, several scholars have suggested different theoretical framework. In this section, a brief review on the framework for studying the growth path of the enterprises is provided.

Penrose (1959) has suggested that enterprises are a bundle of internal and external resources, which helps an enterprise to achieve competitive advantage. She further adds that in the long run, there can be a limit to the growth of an enterprise, but not to the size. Growth of an enterprise is determined by the rate at which experienced managerial staff can plan and implement this plan. She has further explained that the external environment of an enterprise is an image in the mind of the entrepreneur. Enterprise activities are governed by productive opportunities which are actually a dynamic interaction between the internal and the external environments. This interaction includes all the productive possibilities that the entrepreneur can see and take advantage of. The author also mentioned that growth often is natural and normal, a process that will occur whenever conditions are favorable. The size of the enterprise is incidental to the growth process, and 'an enterprise is a coherent administrative unit that provides administration coordination and authoritative communication' (Penrose 1959: Xi, 20). She has proposed that the growth of the enterprise is limited by the scope of managerial resources, specially the ability to coordinate capabilities and introduce new people into the enterprise.

Greiner (1972) has done the foundational work on the theory of enterprise development. Based on his theoretical review of growing enterprises, he has concluded that enterprises move through five distinguishable stages of growth. Each phase contains a relatively calm period of growth that ends with a management crisis (see Masurel and Montfort 2006). These five phases and crises of growth are creativity, direction, delegation, coordination, and collaboration (Figure 1).

He suggests that an enterprise goes through evolution and revolution crises. These crises can be solved by introducing new structures and programs that will help employees to revitalize them. Greiner's phenomena of evolution and revolution became the basis of many studies on enterprise life cycle. Another significant contributor in this field is Adizes (1979) who argues that the attitude and style of a manager has a lot of influence on the life and effectiveness of an enterprise (see Masurel and Montfort

Creativity Direction Delegation Coordination Collaboration

Figure 1 Phases and crises of growth (Masurel and Montfort 2006). 
2006). Adizes has also pointed out that reinforcement skills, self-commitment, risktaking capacity, vision, and administrative mastery are required in the first few stages of an enterprise development. Once an enterprise reaches its prime stage, the manager needs to be result-oriented and should show proper planning and coordination skills. At the maturity stage, the enterprise should be backed by systems to achieve the target.

Applying the findings of Greiner to the small entrepreneurial business situation, Churchill and Lewis (1983) have developed a model. As defined by them, an enterprise can have five stages of growth as depicted below (Figure 2).

Existence is the first of the entrepreneurial venture. In this stage, the enterprise struggles to establish its processes and works without a formal structure in place. The owner of the enterprise takes close supervision of each and every business activity.

At the second stage, which is survival, the business grows and the entrepreneur feels the need to have additional capital to expand the business. Since the business activity is growing, he/she prefers to add family members or known people as partners to expand the business. The main aim of the enterprise is to reach the breakeven point so that adequate cash flow can be maintained to meet day-to-day requirements of repair and replacements.

At the third stage of success, the enterprise begins to earn profits. They have enough capital to either invest in further business opportunity or continue with the same pace of growth. At this stage, the enterprise may take up team building and people development as some of their focus areas; however, these initiatives are driven by personal values and vision of the entrepreneur.

At the takeoff stage, the focus is on further growth, expansion, and seeking new opportunities. The organization becomes more formal in nature, and work is properly defined and delegated. Finally, at the resource maturity stage, the enterprise is no more called a small enterprise. Company gives more emphasis on quality control, financial control, and creating a niche in the market.

Bridge et al. (2003) suggest that it is not necessary that an enterprise develops in discrete phases with clear boundaries between them. They further highlighted that 'separating the development process into stages is rather like dividing the spectrum of visible light into colors'. The authors argue that, while broad stages of development of an enterprise can be indicted, it is very difficult to say when the business moves from one stage to another. Enterprises do not necessarily follow the linear models. It is not possible for an enterprise to progress through each stage. They can grow, stagnate, and decline in any order; also, these things can happen more than once, and there is a possibility to reverse their steps. Authors suggest that the growth of an organization is a result of many discrete efforts. As also suggested by Blundel and Hingley (2001), growth may be achieved quickly, slowly, or not at all. It depends on the strength of the growth aspirations and growth-enabling factors of an enterprise. Hence, it is not possible to consider growth as a norm or an even progression of an enterprise.

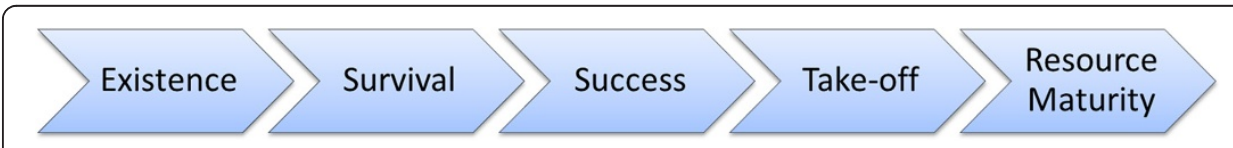

Figure 2 Stages of an enterprise growth (Churchill and Lewis 1983). 
Levie and Lichtenstein (2010) have suggested that the stages model and life cycle theories of entrepreneurial growth do not provide ample evidences of the enterprise growth and development. In their review of literature of the last 40 years, they have found that there is no agreement on defining the stages of enterprise growth. Further, they have pointed out that previous researches lack proper evidences on what is the path of progress from one stage to another and the reasons behind the shift. They have suggested a new dynamic stage theory which argues that organizations are not like organisms, and their growth can be co-created with the help of shifting of internal as well as external environment. Dynamic states offer that an enterprise can survive and maintain itself by being flexible and by adapting continuous changes in the environment. The author highlights the need to have a sustainable growth approach instead of growing on the basis of number of stages. Though the authors strongly recommend the use of dynamic stage theory, they conclude that an empirical research is required to find out what makes dynamic state sustainable, when and where dynamic states change, and which contextual variables are important for the processes. Leitch et al. (2010) also suggest that there is a need to understand the growth phenomenon and its importance to conceptualize the phenomenon properly. There is a lack of shared understanding on the causes, effects, and the process of growth. In the above paragraph, it was mentioned that growth is a social construct (Majumdar 2008); hence, there is lot of diversity in it. The heterogeneity of the enterprise and entrepreneur's context add further challenges to the study and understanding of growth. Leitch et al. (2010) also observe that three questions related to growth have been addressed at least to some extent: why, how, and how much. They further suggest that there is still a lot of scope of exploration on growth as 'internal process of development' (Penrose 1959).

Chaston (2010) in his book has suggested that under the life cycle concept of an enterprise, a new chasm has to be crossed before the next stage of growth can be commenced. Chasms are of five types: launch capacity, expansion, organizational formalization, succession, and long-term growth (Figure 3).

Crossing each chasm will require the entrepreneur to acquire new skills and prioritize managerial task inside the organization. The author further suggests that some of the entrepreneurs may take more time to move from one chasm to another, while for some, it may be a fast progression. Financial backing, non-viable means to new technology, may be the reasons for not able to cross chasm 1 (Dunn and Cheatham 1993). To be able to cross chasm 2, the entrepreneur should be able to generate demand and increase sales. To cross chasm 3, there is a need for capacity expansion. One needs to match the demand with appropriate supply. Failure to implement a formal organization

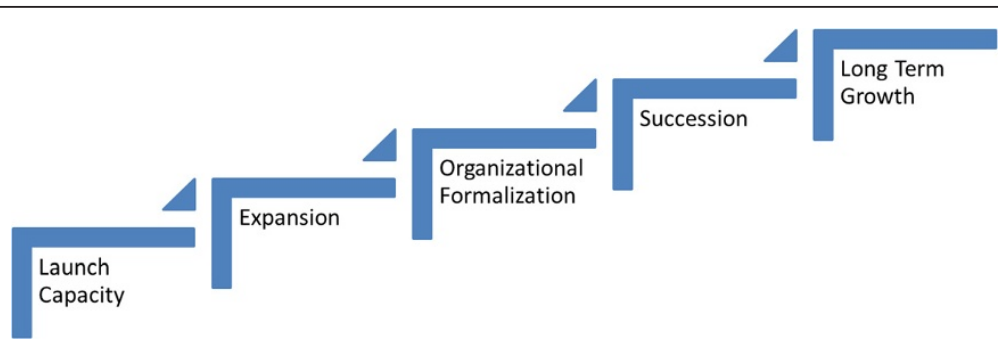

Figure 3 Chasms of growth by Chaston (2010). 
structure with professional manpower will pose challenges to cross chasm 4 (Anonymous 1984). A well-established business will require a competent successor. The entrepreneur may decide to appoint an internal person or bring a new chief executive from the outside of the company. An ineffective replacement for the founder may cause the business to fail to cross chasm 5 (Ip and Jacobs 2006).

To summarize, there are two theoretical frameworks of enterprise growth:

The predictable framework defines that the growth path can be linear, sequential, deterministic, and invariant (Churchill and Lewis 1983; Greiner 1972; Adizes 1979; Kimberly 1979; Hanks et al. 1993). There are different thoughts on defining the growth path of an enterprise in a predictable way starting from existence, survival, success, takeoff, maturity, and then reinvention or death (Churchill and Lewis 1983; Casson 1982). The enterprise competitiveness continuously increases from the startup stage to maturity stage. At the decline stage, the competitiveness of the enterprise weakens and signals that in case the enterprise do not upgrades itself, it will fall. Chen et al. (2008) suggest that the enterprise at different life cycle stages should focus on strengthening capabilities.

The other school of thoughts suggests that there can be abrupt changes in the growth path especially in small enterprises. Recent researches have shown that due to unpredictable intervening factors like knowledge and technology, absorption capabilities, appropriateness of the founder's judgment, and competitive environment, the sequences of stages may be heterogeneous in small enterprises. Phelps et al. 2007, Aislabie 1992, Levie and Hay 1998, Rutherford et al. 2003, and Stubbart and Smalley 1999 have argued that the life cycle models and the deterministic approach to growth are not relevant to organizations. The authors' points out that describing an enterprise growth through a series of stages is equivalent to assuming an organization growth as organism metaphor. Majumdar (2008) has suggested that the enterprise growth depends upon the entrepreneurial vision and stand point. He has further suggested that entrepreneurship is not only maintaining a status quo but also making the enterprise grow.

Enterprise growth depends on the vision and motivation of the entrepreneur. The growth parameters vary from one entrepreneur to another. The environment in which the enterprise is operating (such as social setting, formal or informal structure of the organization, country origin and its culture, and family) has different implications on the enterprise growth. Summaries of models have been done by Quinn and Cameron (1983), Phelps et al. (2007), and Levie and Lichtenstein (2010). These provide the evidences on the common propositions about organization growth. However, there is a lack of integration among these studies, and one cannot draw any conclusion out of them.

Business environment can be perceived through four theoretical frameworks (see Davidsson and Wiklund 2000). When the focus of the enterprise is on its resources like expansion of business activities, financial resources, educated staff, etc., the growth is to be studied from the resource-based perspective. Growth studies applying strategic adaptation as a perspective would focus more on power distribution, structural complexities, and control mechanisms. The third theoretical perspective of an enterprise growth will be motivation perspective which focuses on the individual and their actions. Lastly, configuration perspective deals with the growth process focusing on managerial problems and how they can be dealt with at various stages of growth. The scope of this study will cover the first perspective of enterprise growth, i.e., resource-based. 


\section{Research gaps}

The literature review suggests that entrepreneurial growth has been an area of interest for policy makers, practitioners, and researchers. Many aspects of enterprise growth have been studied in the last 50 years, but there are very few studies conducted on the growth path followed by SMEs in different context. Majority of the literature emphasizes on the growth of an enterprise through a predetermine path (Greiner 1972; Adizes 1979; Kimberly 1979; Churchill and Lewis 1983; Hanks et al. 1993). However, in the last couple of decades, there are some researches suggesting that the sequence of stages of growth can be heterogeneous (Aislabie 1992; Levie and Hay 1998; Rutherford et al. 2003; Stubbart and Smalley 1999; Phelps et al. 2007) due to intervening external and internal factors. The literature on alternative growth path like jumps (Aislabie 1992), skipping stages (Masurel and Montfort 2006), and alternative way of defining developmental stages of SMEs is not profound.

The growth process of an enterprise may vary from country to country. Though there are many studies on the stage of an enterprise growth, the study on growth pattern of an enterprise influenced by the internal and external environmental factors is limited. There is a need to develop a conceptual framework to study the growth of SMEs as influenced by the various environmental factors.

\section{Suggested framework}

Ardishvili et al. (1998) classified empirical growth research as either factors of growth studies or growth process studies. Environmental factors effecting the growth of enterprise can broadly be classified into two categories, i.e., internal and external factors (ICFAI 2001). Environment is defined as an 'aggregate of all conditions, events and influences that surround and affect it'. It can be divided into external and internal components for better understanding.

- The internal factors are those which are controllable and comprise the enterprise's personnel, its strategy, and its functional, operational, marketing, financial, and technical capabilities.

- The external factors are beyond the control of the enterprise and comprise economic, sociocultural, regulatory and legal, political, financial, trade, technological, demographics, geophysical factors, etc.

In order to choose an appropriate unit of analysis, the factors (internal and external) connected with growth of an enterprise (business environment) are briefly given below:

1. External factors. All the factors that provide opportunities or threats to an organization make up the external environment of the organization. In a broader sense, it encompasses a variety of factors discussed below:

Demographic environment includes factors like size, growth rate, age composition, sex compositions, etc. of the population. The heterogeneity of demographics in terms of varied tastes, preferences, beliefs, temperaments, etc. affects the demand patterns of populations, and the enterprises need to make different strategies accordingly. Social environmental factors include human relationships and its effects on the society, hence the growth of an organization. Cultural environment 
and understanding of which are important to understand the business environment in its totality. Understanding a particular culture and its proper analysis provide opportunities to establish and run a business. The term political environment refers to the factors related to the management of public affairs and their impact on the growth of an organization. Economic environment encompasses economic planning like five-year plans, budgets, and monetary, fiscal, and industrial policies. Thus, economic system is a very important determinant of the scope of enterprises and, therefore, a very important external factor influencing business growth.

a) Business enterprises are closely associated with financial environment. To reduce the uncertainty arising out of the dynamic nature of financial environment, it is important to understand the pulse of money market and capital market. In pursuance of the broad objective, World Trade Organization has been established and its preview, General Agreement on Trade in Services. The Agreement on Trade-Related Aspects of Intellectual Property Rights and the Agreement on Trade-Related Investment Measures have been brought. These have made the trade environment one of the deciding factors affecting the future of a business. The technological environment has a huge impact on the growth of a business. It comprises factors related to applied knowledge and the materials and machines used in the production of goods and services. Enterprises are corporate entities and have to abide by the law of the land; every country has its own system of law. Each country has its different legal systems with varied complexity and dimension. Hence, it is essential that an enterprise operating in global environment understands and abide by the global laws. The regulatory factors comprise the factors related to planning, promotion, and regulation by the government. Some of the factors which influence the regulatory environment include the constitutional framework, directive principles of state policy, fundamental rights, and division of legislative power between central and state governments. These factors also include policies related to import/export, distribution, pricing, public sector, small scale industries, sick industries development, etc. Other external factors effecting business environment would include tax environment and ethical environment.

2. Internal factors. The internal environment comprises resources, synergy, and distinctive competencies of a firm. All these together determine organizational capability in terms of its strengths and weaknesses existing in different functional areas like marketing, operations, personnel, financial, technical, etc. Business managers need to monitor the business opportunities and threats that have or likely to have an impact on their organization. However, the internal environment is constantly influenced by the external environment.

The strategy of an organization indicates the course of action to achieve the set objectives. This involves an analysis of the organizational factors (internal and external) with the environmental factors (opportunities and threats). The organizational structure of an enterprise is affected by a number of factors like size of the business, the nature of the business, the diversity of the business, the characteristics of the market, the characteristics of the strategy, the future plans of the organizations, etc. A flexible 
organizational structure enables the organization to quickly and effectively respond to the changes in the market. Marketing capability factors are those related to the pricing, promotion, and distribution of products or services. Operations capability factors are those that are directly related to productions. It involves factors like capacity, location, layout, product or service design, degree of automation, extent of vertical integration, etc. Personnel capability is one of the most important factors influencing business environment. This factor is related to the existence and use of human resources and skills in the enterprise. It has significant bearing on the capacity and ability of an organization to implement its strategy. Personnel capability would involve factors related to acquiring, maintaining, developing, and training people. It will also take care of factors related to industrial relations, organizational and employees' characteristics such as corporate image and working conditions. Financial capability factors include all those factors which are related to the availability, usage, and management of funds. To keep pace with the changing business scenario, organizations are giving a lot of importance to its technical capabilities. It is important to improve productivity and quality in this fierce competitive era. This objective can be met though continuous improvement in the work structure, procedure, and technologies. Technical people of an enterprise may bring this competitive advantage.

\section{Conclusions}

It is important to understand the growth path of an enterprise. The study of growth prepares the owners/mangers to take strategic decisions and lay out expansion plans. The above mentioned literature review suggests that there are many studies on identifying the stage of an enterprise growth, but there is a dearth of data on how these enterprises grow and what the influencing factors are. In each geography, the characteristics of enterprises differ. They are unique and operate in unique social economic conditions. There is a need to study how the internal and external environmental factors affect the growth path followed by the enterprises. Under specific conditions, the subset of the factors can also be taken for more intensive study. Further scope of the study could be on how the growth of the SMEs be integrated with sustainable development and innovation. There have been recent studies on how innovation can stimulate sustainable development, but there is no significant work done covering SMEs. There should be empirical research on how internal and external factors contribute in sustainable innovativeness in SMEs. In the same regard, as pointed by Carayannis et al. (2012), innovation can be described by 'Quintuple Helix Model' which has five helixes, i.e., the education system, economic system, natural environment, and media-based and culture-based public and the political system. All these helixes have critical role to play in determining the enterprise growth path as well. However, future researchers can study how these helixes, individually as well as collectively, can facilitate or impede growth of enterprises. 


\section{Author details}

${ }^{1}$ Symbiosis Centre for Management and Human Resource Management, Pune 4110457, India. ${ }^{2}$ Tata Institute of Social Sciences, Mumbai 400088, India.

Received: 28 December 2012 Accepted: 7 May 2013

Published: 17 June 2013

\section{References}

Adizes, I. (1979). Organizational passages_diagnosing and treating lifecycle problems of organizations. Organizational Dynamics, 8, 3-25.

Aislabie, C. (1992). Sudden changes in a model of small firm growth. Small Business Economics, 4(4), 307-314.

Anonymous. (1984). Problems tracked in transition from owner to professional management. Journal of Accountancy, 158(4), 38-41.

Ardishvili, A, Cardozo, S, Harmon, S, \& Vadakath, S. (1998). Towards a theory of new venture growth. Ghent, Belgium: Paper presented at the 1998 Babson Entrepreneurship Research Conference.

Barringer, BR, \& Bluedorn, AC. (1999). The relationship between corporate entrepreneurship and strategic management Strategic Management Journal, 20(5), 421-444.

Bartlett, W, \& Bukvic, V. (2001). Barriers to SME growth in Slovenia. MOCT-MOST: Economic Policy in Transitional Economies, 11, 177-195.

Baumol, WJ. (2004). Entrepreneurial enterprises, large established firms and other components of the free-market growth machine. Small Business Economics, 23(1), 9-21.

Blundel, RK, \& Hingley, M. (2001). Exploring growth in vertical inter-firm relationships: small-medium firms supplying multiple food retailers. Journal of Small Business and Enterprise Development, 8(3), 245-265.

Bougrain, F, \& Haudeville, B. (2002). Innovation, collaboration and SMEs internal research capacities. Research Policy, 31 , 735-747.

Bridge, S, O'Neill, K, \& Cromie, S. (2003). Understanding enterprise, entrepreneurship and small business. London: Palgrave Macmillan.

Carayannis, EG, Barth, TD, \& Campbell, FJ. (2012). The quintuple helix innovation model: global warming as a challenge and driver for innovation. Journal of Innovation and Entrepreneurship, 1, 2.

Carton, RB, Hofer, CW, \& Meeks, MD. (1998). The entrepreneur and entrepreneurship: operational definitions of their role in society. Paper presented at the annual International Council for Small Business Conference, Singapore.

Casson, M. (1982). The entrepreneur: an economic theory. Oxford: Martin Robertson.

Chaston, I. (2010). Entrepreneurial management in small firms (pp. 53-72). London: Sage Publications.

Chaston, I, \& Mangles, T. (1997). Core capabilities as predictors of growth potential in small manufacturing firms. Journal of Small Business Management, 35(1), 47-57.

Chen, M, Cao, Y, \& Ma, Y. (2008). An empirical research on the evolution model of competitiveness between different life cycle stages in Chinese enterprises. Journal of Combinatorics, Information \& System Sciences, 6(4), 351-370.

Churchill, NC, \& Lewis, VL. (1983). The five stages of small business growth. Harvard Business Review, 61(3), 30-50.

Curran, J. (2000). What is small business policy in the UK for? Evaluation and assessing small business policies. International Small Business Journal, 18(3), 36-51.

Curran, J, \& Blackburn, RA. (1994). Small firms and local economic networks: the death of the local economy. London: Paul Chapman Publishing.

Davidsson, P. (1989). Entrepreneurship - and after? A study of growth willingness in small firms. Journal of Business Venturing, 4, 211-226

Davidsson, P, \& Delmar, F. (1997). High-growth firms: characteristics, job contribution and method observations. Mannhiem: RENT XI Conference.

Davidsson, P, \& Wiklund, J. (2000). Conceptual and empirical challenges in the study of firm growth. In D Sexton \& H Landström (Eds.), The Blackwell handbook of entrepreneurship (pp. 26-44). Oxford: Blackwell Business.

Dunn, P, \& Cheatham, L. (1993). Fundamentals of small business financial management for start up, survival, growth, and changing economic circumstances. Managerial Finance, 19(8), 1-14.

Evans, DS. (1987). The relationship between firm growth, size and age: estimates for 100 manufacturing industries. The Journal of Industrial Economics, 35(4), 567-581.

Fazzari, SM, Hubbard, RG, \& Petersen, BC. (1988). Financing constraints and corporate investment. Brookings Papers on Economic Activity, 1, 141-195.

Freel, MS, \& Robson, PJA. (2004). Small firm innovation, growth and performance. International Small Business Journal, 22(6), 561-575.

Gaskill, LR, Van Auken, HE, \& Manning, RA. (1993). A factor analytic study of the perceived causes of small business failure. Journal of Small Business Management, 31(4), 18-31.

Gibb, AA. (2000). SME policy, academic research and the growth of ignorance, mythical concepts, myths, assumptions, rituals and confusions. International Small Business Journal, 18(3), 13-36.

Gilbert, BA, McDougall, PP, \& Audretsch, DB. (2006). New venture growth: a review and extension. Journal of Management, 32, 926.

Greiner, L. (1972). Evolution and revolution as organizations grow. Harvard business review. Journal of Small Business Management, 472, 37-46.

Hamilton, RT, \& Dana, LP. (2003). An increasing role for small business in New Zealand. Journal of Small Business Management, 41(4), 402-408.

Hanks, S, Watson, C, Jansen, E, \& Chandler, G. (1993). Tightening the life-cycle construct: a taxonomic study of growth stage configurations in high-technology organizations. Entrepreneurship Theory and Practice, 18, 5-29.

Heshmati, A. (2001). On the growth of micro and small firms: evidence from Sweden. Small Business Economics, 17(3), 213-228.

ICFAI. (2001). Business environment. Hyderabad: The ICFAI Centre for Management Research. 
Ip, B, \& Jacobs, G. (2006). Business succession planning: a review of the evidence. Journal of Small Business and Enterprise Development, 13(3), 326-338.

Kimberly, JR. (1979). Issues in the creation of organizations: initiation, innovation, and institutionalization. Academic Manage Journal, 22, 437-457.

Kolvereid, L, \& Bullvag, E. (1996). Growth intentions and actual growth: the impact of entrepreneurial choice. Journal of Enterprising Culture, 4(01), 1-17.

Kruger, ME. (2004). Entrepreneurial theory and creativity (chapter 2). University of Pretoria. http://upetd.up.ac.za/thesis/ available/etd-08242004-145802/unrestricted/02chapter2.pdf. Accessed on 19 ${ }^{\text {th }}$ June 2013.

Kuratko, DF. (2009). Entrepreneurship, theory, process and practice (pp. 1-22). Nashville: South Western Publication.

Leitch, C, Hill, F, \& Neergaard, H. (2010). Entrepreneurial and business growth and the quest for a 'comprehensive theory': tilting at windmills? Entrepreneurship Theory and Practice, 34(2), 249-260.

Levie, J, \& Hay, M. (1998). Progress or just proliferation? A historical review of stages models of early corporate growth. London: London Business School.

Levie, J, \& Lichtenstein, B. (2010). A terminal assessment of stages theory: introducing a dynamic states approach to entrepreneurship. Entrepreneurship: Theory \& Practice, 34(2), 317-350.

Lokhande, M. (2011). Financial inclusion: options for micro, small and medium enterprises. Synergy, 9(2), 39-50.

Lorunka, C, Kessler, A, Frank, H, \& Lueger, M. (2011). Conditions for growth in one-person startups: a longitudinal study spanning eight years. Psicothema, 23(3), 446-452.

Lumpkin, GT, \& Dess, GG. (1996). Clarifying the entrepreneurial orientation construct and linking it to performance. Academy of Management Review, 21(1), 135-172.

Majumdar, S. (2007). Growth strategy in small manufacturing organizations: a study of Madhya Pradesh and Maharashtra. In S Bhargava (Ed.), Developmental aspects of entrepreneurship (pp. 112-157). London: Sage Publication.

Majumdar, S. (2008). Modeling growth strategy in small entrepreneurial business organizations. Journal of Entrepreneurship, 17, 157.

Masurel, E, \& Montfort, KV. (2006). Life cycle characteristics of small professional service firms. Journal of Small Business Management, 44(3), 461-473.

Mateev, M, \& Anastasov, Y. (2010). Determinants of small and medium sized fast growing enterprises in central and eastern Europe: a panel data analysis. Financial Theory and Practice, 34(3), 269-295.

Mitra, R, \& Pingali, V. (1999). Analysis of growth stages in small firms: a case study of automobile ancillaries in India. Journal of Small Business Management, 37(3), 62-76.

Morone, P, \& Testa, G. (2008). Firms' growth, size and innovation - an investigation into the Italian manufacturing sector. Economics of Innovation and New Technology, 17(4), 311-329.

Muthaih, K, \& Venkatesh, S. (2012). A study on the barriers affecting the growth of small and medium enterprises in India. International Journal of Research in Computer Application Management, 02(1), 77-81.

Noteboom, B. (1991). Strengths and weaknesses of small businesses in innovation and diffusion. Rio de Janeiro: TIMS/ SOBRAPO Conference.

Pajarinen, M, Rouvinen, P, \& Ylä-Anttila, P. (2006). Uusyrittä jien kasvuhakuisuus, KTM julkaisuja 29/2006. Helsinki: Ministry of Employment and the Economy.

Penrose, E. (1959). The theory of the growth of the firm. Oxford: Oxford University Press.

Phelps, R, Admas, R, \& Bessant, J. (2007). Life cycle of growing organizations: a review with implications for knowledge and learning. International Journal of Management Reviews, 9(1), 1-30.

Quinn, R, \& Cameron, K. (1983). Organizational life cycles and shifting criteria of effectiveness: some preliminary evidence. Management Science, 29(1), 33-51.

Rahman, S. (2001). A comparative study of TQM practice and organizational performance of SMEs with and without ISO 9000 certification. International Journal of Quality \& Reliability Management, 18(1), 35-49.

Robbins, DK, Pantuosco, LJ, Parker, DF, \& Fuller, BK. (2000). An empirical assessment of the contribution of small business employment to US state economic performance. Small Business Economics, 15(4), 293-302.

Rothwell, R. (1986). The role of small firms in technological innovation. In J Curran, J Stanworth, \& D Watkins (Eds.), The survival of the small firm (pp. 114-139). Aldershot: Gower.

Rutherford, MW, Buller, PF, \& Mcmullen, PR. (2003). Human resource management problems over the life-cycle of small to medium-sized firms. Human Resource Management, 42, 321-335.

Schumpeter, JA. (1934). The theory of economic development. Cambridge: Harvard University Press.

Smallbone, D, \& Wyer, P. (2000). Growth and development in the small firm. In S Carter \& D James-Evans (Eds.) Enterprise and small business (pp. 391-400). Harlow: Prentice Hall.

Stubbart, Cl, \& Smalley, RD. (1999). The deceptive allure of stage models of strategic processes. Journal of Management Inquiry, 8, 273-287.

The Business World. (2010). The SME Whitebook (2009-2010): essential handbook for small and medium enterprise. New Delhi: Business World

Tonge, R, Larsen, P, \& Roberts, M. (2000). Information systems investment within high-growth medium-sized enterprises Management Decision, 38(7), 489-502.

Westhead, P, \& Birley, S. (1995). Employment growth in new independent owner-managed Great Britain. International Small Business Journal, 13(3), 1-29.

Wickham, P. (2006). Strategic entrepreneurship (4th ed.). London: Financial Times Prentice-Hall.

doi:10.1186/2192-5372-2-15

Cite this article as: Gupta et al:: Firm growth and its determinants. Journal of Innovation and Entrepreneurship 2013 2:15. 